\title{
Neurodevelopmental phenotypes in individuals with pathogenic variants in CHAMP1
}

\author{
Madison Garrity, ${ }^{1}$ Haluk Kavus ${ }^{2}$ Marta Rojas-Vasquez, ${ }^{3}$ Irene Valenzuela, ${ }^{4}$ \\ Austin Larson, ${ }^{5}$ Sara Reed, ${ }^{6}$ Gary Bellus, ${ }^{6}$ Cyril Mignot, ${ }^{7}$ Arnold Munnich, ${ }^{8}$ \\ Bertrand Isidor, 9,10 and Wendy K. Chung ${ }^{2,11}$
}

\begin{abstract}
${ }^{1}$ Columbia University School of Dental Medicine, New York, New York 10032, USA; ${ }^{2}$ Department of Pediatrics, Columbia University Medical Center, New York, New York 10032, USA; ${ }^{3}$ Department of Pediatric HematologyOncology, Stollery Children's Hospital, Edmonton, Alberta T6G 2B7, Canada; ${ }^{4}$ Department of Clinical and Molecular Genetics, Hospital Vall d'Hebron, 08035 Barcelona, Spain; ${ }^{5}$ Section of Clinical Genetics and Metabolism, Department of Pediatrics, University of Colorado, Aurora, Colorado 80045, USA; ${ }^{6}$ Clinical Genetics and Genomic Medicine, Geisinger Health System, Danville, Pennsylvania 17821, USA; ${ }^{7}$ APHPSorbonne Université, Département de Génétique, Hôpital Trousseau et Groupe Hospitalier Pitié-Salpêtrière, 75013 Paris, France; ${ }^{8}$ Imagine Institute, INSERM UMR 1163, Université de Paris; Fédération de Génétique Médicale, Assistance Publique-Hôpitaux de Paris, Hôpital Necker-Enfants Malades, 75015 Paris, France; ${ }^{9}$ Service de Génétique Médicale, CHU Nantes, 44093 Nantes Cedex 1, France; ${ }^{10} \mathrm{~L}$ 'Institut du Thorax, INSERM, CNRS, Université de Nantes, 44007 Nantes, France; ${ }^{11}$ Department of Medicine, Columbia University Medical Center, New York, New York 10032, USA
\end{abstract}

Abstract De novo pathogenic variants in CHAMP1 (chromosome alignment maintaining phosphoprotein 1), which encodes kinetochore-microtubule associated protein on 13q34, cause a rare neurodevelopmental disorder. We enrolled 14 individuals with pathogenic variants in CHAMP1 that were documented by exome sequencing or gene panel sequencing. Medical history interviews, seizure surveys, Vineland Adapted Behavior Scales Second Edition, and other behavioral surveys were completed by primary caregivers of available participants in Simons Searchlight. Clinicians extracted clinical data from the medical record for two participants. We report on clinical features of 14 individuals (ages 2-26) with de novo predicted loss-of-function variants in CHAMP1 and compare them with previously reported cases (total $n=32$ ). At least two individuals have the same de novo variant: p.(Ser181Cysfs*5), p.(Trp348*), p.(Arg398*), p.(Arg497*), or p.(Tyr709*). Common phenotypes include intellectual disability/developmental delay, language impairment, congenital and acquired microcephaly, behavioral problems including autism spectrum disorder, seizures, hypotonia, gastrointestinal issues of reflux and constipation, and ophthalmologic issues. Other rarely observed phenotypes include leukemia, failure to thrive, and high pain tolerance. Pathogenic variants in CHAMP1 are associated with a variable clinical phenotype of developmental delay/intellectual disability and seizures.

[Supplemental material is available for this article.]

\section{INTRODUCTION}

Neurodevelopmental disorders (NDDs) such as intellectual disability (ID) and autism spectrum disorder (ASD) are both genetically and phenotypically heterogeneous. Because of the pleiotropic nature and genetic heterogeneity of these conditions, exome sequencing (ES) is an initial diagnostic approach for individuals with NDDs (Srivastava et al. 2019). 
COLD SPRING HARBOR Molecular Case Studies
Clinical features of patients with CHAMP1 variants
CHAMP1 (MIM: 616327), located on 13q34, encodes an 812-amino acid zinc finger phosphoprotein. CHAMP1 protein functions to maintain proper kinetochore-microtubule attachment and chromosome alignment on the metaphase plate (Itoh et al. 2011). The first three patients with CHAMP1 variants associated with a developmental disorder were identified in the Deciphering Developmental Disorders Study of 1133 children with severe developmental disorders (Fitzgerald et al. 2015). Subsequently, six additional manuscripts identified 20 additional individuals. These publications included data on individuals with 12 nonsense variants (60\%), six frameshift variants (30\%), one missense variant (5\%), and one microdeletion including CHAMP1 (5\%) (Hempel et al. 2015; Isidor et al. 2016; Tanaka et al. 2016; Okamoto et al. 2017; Ben-Haim et al. 2020; Wang et al. 2020).

Common clinical manifestations of individuals with the CHAMP1 disorder include intellectual disability, speech and language impairment, motor developmental delay, microcephaly, seizures, ophthalmologic issues, hypotonia, and dysmorphic facial features (Hempel et al. 2015; Isidor et al. 2016; Tanaka et al. 2016; Okamoto et al. 2017; Ben-Haim et al. 2020; Wang et al. 2020). In this study, we refine the phenotype associated with de novo pathogenic/likely pathogenic variants in CHAMP1 in 12 previously unreported individuals enrolled in Simons VIP/Searchlight by providing data on clinical features and standardized neurobehavioral measures. We also include a single case with leukemia. Characterization of additional patients is necessary to determine whether cancer is more common in individuals with CHAMP1 variants.

\section{RESULTS}

\section{Molecular Findings}

We analyzed 12 new individuals and two previously reported individuals (Isidor et al. 2016; Tanaka et al. 2016) with pathogenic or likely pathogenic variants in CHAMP1 identified on clinical testing. Among these 14 individuals, there are 11 nonsense and three frameshift variants, all of which were de novo and predicted to result in nonsense-mediated decay (Table 1). The c.1489C > T; p.(Arg497*) variant is recurrent and was independently identified in four unrelated individuals in our cohort and one previously reported individual (Isidor et al. 2016). The c.542_543delCT; p.(Ser181Cysfs*5) variant is also recurrent and has been independently reported in two unrelated individuals, one in our cohort and one previously reported (Tanaka et al. 2016). The other recurrent variants were p.(Trp348*), p.(Arg398*), and p.(Tyr709*). All other variants are unique to a single individual.

\section{Clinical Findings}

Of the 14 individuals, eight are females and six are males. The average age at assessment was $9.3 \mathrm{yr}$, with a range from $2.2 \mathrm{yr}$ to $26.3 \mathrm{yr}$. Three individuals had prenatal/perinatal complications including small gestational age observed during ultrasound $(14.3 \%)$ or a broken clavicle (7.1\%). Seven individuals had complications prior to newborn hospital discharge including respiratory distress (35.7\%), neonatal jaundice (35.7\%), and abnormal hearing (21.4\%). Twelve individuals had neonatal symptoms of feeding difficulty (35.7\%), hypotonia (35.7\%), lethargy (28.6\%), irritability (21.4\%), and difficulty sucking (21.4\%).

All individuals demonstrated delayed developmental milestones (Table 1; Supplemental Table 1). Developmental milestones include sitting at an average age of 15.9 mo, walking at an average age of 33.9 months ( $n=1$ achieved past the age of $7 ; n=1$ did not acquire), first words spoken at an average age of $35 \mathrm{mo}(n=1$ achieved past the age of $7 ; n=2$ did not acquire), and self-feeding achieved at an average age of $60 \mathrm{mo}(n=3$ achieved past the 


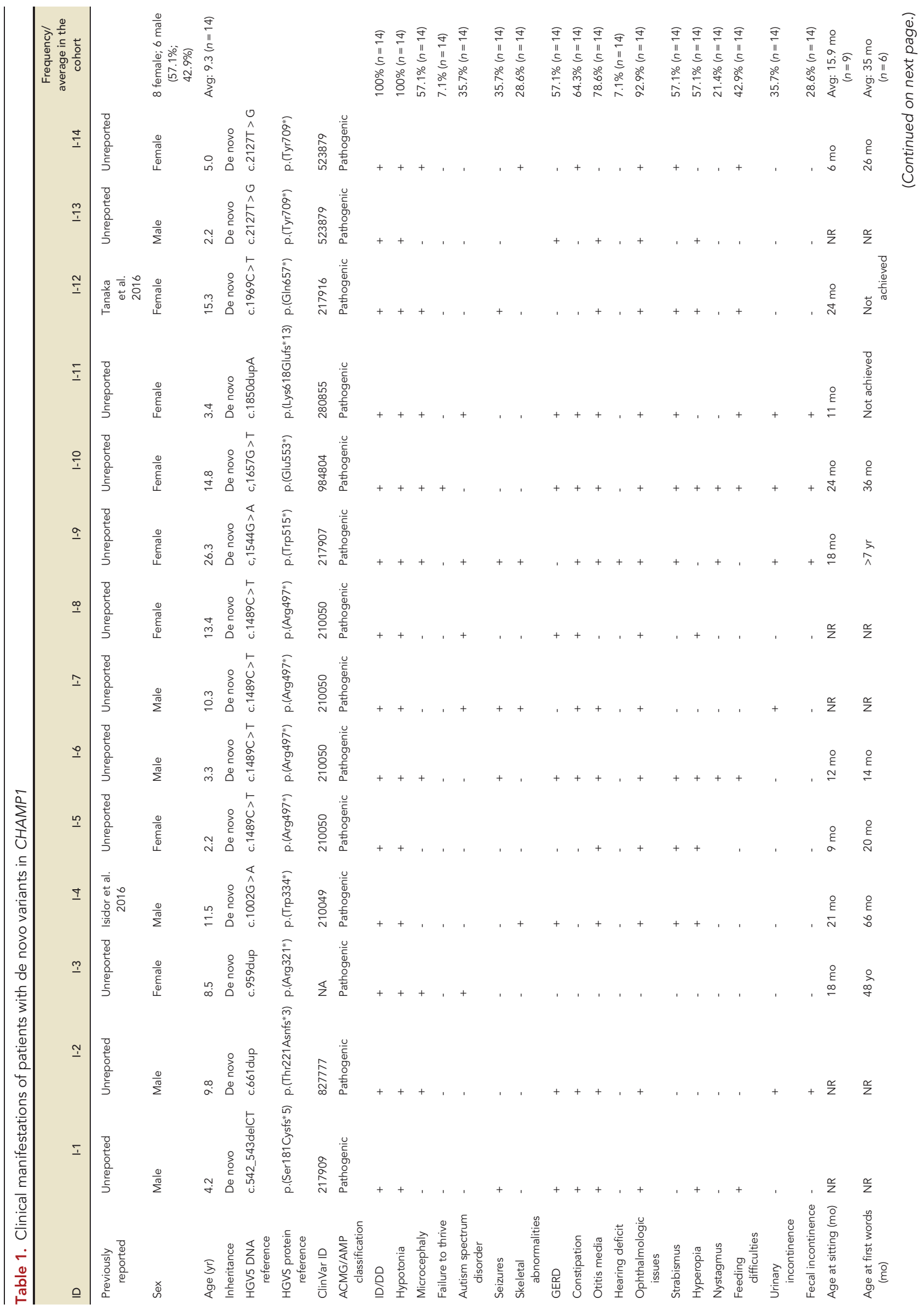




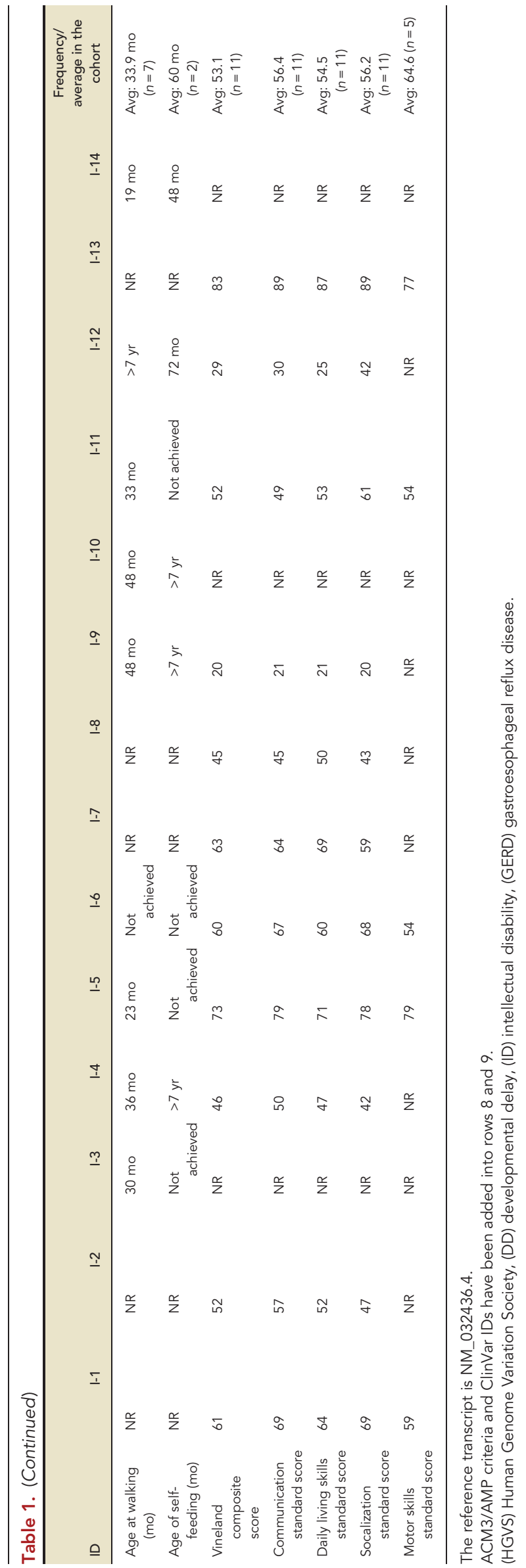


age of $7 ; n=3$ did not acquire). Urinary incontinence (35.7\%) and fecal incontinence (28.6\%) were observed ranging in ages from 3.4 to $26.3 \mathrm{yr}$ old.

All of the individuals had neurological manifestations including intellectual disability or developmental delay (100\%), hypotonia (100\%), congenital microcephaly $(21.4 \%)$, acquired microcephaly (21.4\%), clumsiness (21.4\%), and movement abnormalities (14.3\%). There was no history of developmental regression.

Other neurobehavioral phenotypes included autism spectrum disorder (35.7\%), nonverbal learning disorder (7.1\%), language dyspraxia (7.1\%), and anxiety (7.1\%).

There have been a number of dysmorphic features seen in our cohort. Hypertelorism, short philtrum, and broad nasal bridge were the common findings (Fig. 1). One patient (I-3) has hypertelorism, anteverted nose, prognathism, syndactyly with doughy skin, and joint laxity (Fig. 1B).

We have brain magnetic resonance imaging (MRI) images for some of our patients. Dysplastic corpus callosum, cerebellar asymmetry, and simplified sulcation were seen in one patient. Another patient had slightly delayed myelination at age 6 (Supplemental Table 1).

We assessed adaptive development in 11 individuals using the Vineland Adaptive Behavior Scales (VABS) assessment of adaptive behaviors (composite score [53.1 \pm 18.1$]$ ). Subscales showed below average scores for all subscales approximately equivalently: communication (56.4 \pm 20.2$)$, daily living skills $(53.5 \pm 18.8)$, socialization ( $57.1 \pm 20.0)$, and motor skills scores (64.6 \pm 12.4 ) (Fig. 2). Nine individuals had low standardized VABS composite scores between 20 and 70 (<-2 SD) and two had moderately low scores between 70 and 80 (<-1 SD) (Sparrow et al. 2005).

For the six individuals who were in the appropriate age range for a VABS motor skills assessment, the average score was $64.6(\mathrm{SD}=12.4$; range $=54-79)$.

Most of the individuals had typical childhood infections (83.3\%, $n=12)$, and no individuals were diagnosed with an immunodeficiency disorder. Most individuals had otitis media
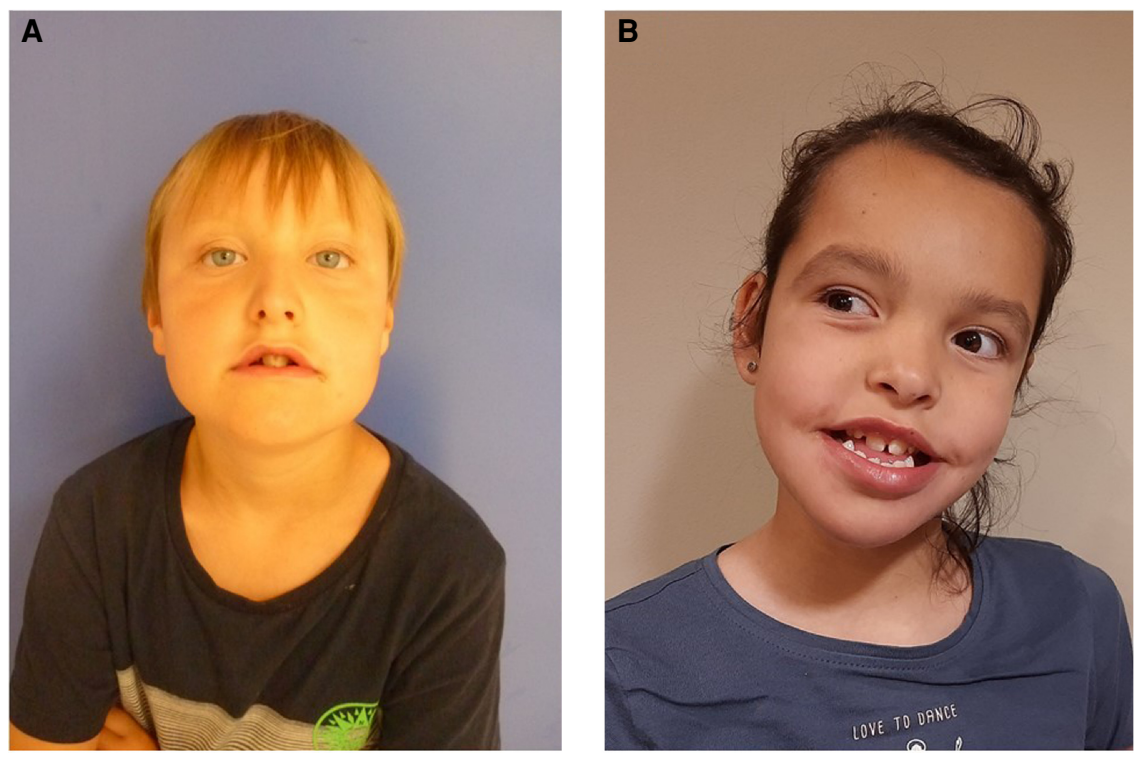

Figure 1. Photographs of patients: (A) I-2 and (B) I-3. Short philtrum, broad nasal bridge, and hypertelorism can be observed in both patients. 
COLD SPRING HARBOR Molecular Case Studies
Clinical features of patients with CHAMP1 variants

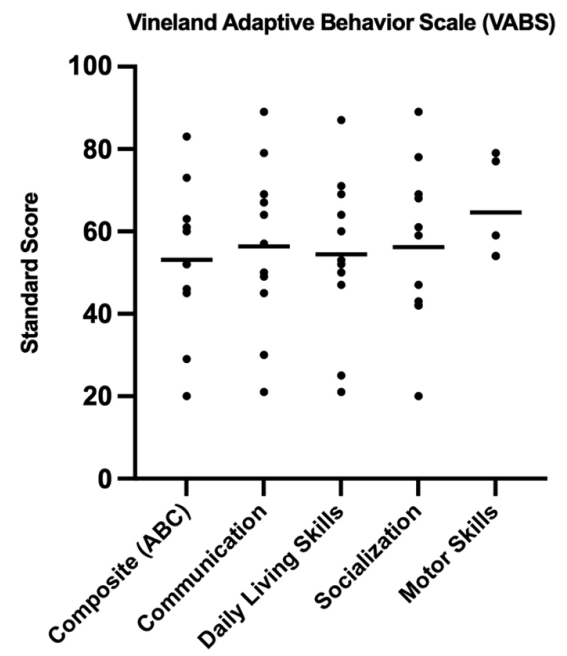

Figure 2. Vineland Adaptive Behavior Scale Scores (edition two) for 11 individuals with averages.

(75\%), some requiring tympanostomy tubes. Pneumonia (41.7\%) and urinary tract infections (8.3\%) were also reported.

Gastrointestinal problems were also commonly reported, including gastroesophageal reflux disease (GERD) (57.1\%) and constipation (64.3\%). Four individuals reported taking laxatives for constipation. One individual requires a gastrostomy tube, and intestinal malrotation was observed once. Weight gain was difficult for one child. Delayed gastric emptying was observed once.

Endocrine problems included short stature (16.7\%), obesity (8.3\%), and irregular menses (8.3\%).

The ophthalmologic issues were another major group of problems (93\%) including alternating esotropia, poor visual attention, delayed visual maturation, intermittent exotropia, bilateral refractive amblyopia, strabismus, and hyperopia.

Five of 14 individuals reported a history of seizures (35.7\%). Two individuals reported complex partial seizures (14.3\%), two reported febrile seizures $(14.3 \%)$, two reported petit mal seizures (14.3\%), and two reported grand mal seizures (14.3\%). One individual had several abnormal electroencephalogram (EEG) results on right occipital region without a clinical seizure. Four individuals had more than one type of seizure. All of these individuals currently have their seizures medically treated and seizures are medically controlled. The two most effective antiepileptics reported were divalproex sodium and levetiracetam.

Other infrequent problems included scoliosis $(28.6 \%)$, apneic episodes $(7.1 \%)$, undescended testicles $(7.1 \%)$, dystonia $(7.1 \%)$, oral sensory hypersensitivity $(7.1 \%)$, and deafness (7.1\%; both conductive and sensorineural hearing loss treated with a hearing aid).

Other notable features included high pain tolerance (41.7\%), sleep issues (35.7\%), and dental issues (21.4\%).

There is one individual in our cohort diagnosed with leukemia (I-7). He is currently $12 \mathrm{yr}$ old and was diagnosed with acute myeloid leukemia with myelodysplasia related changes at $8 \mathrm{yr}$ old. He has a de novo CHAMP1 c.1489C > T; p.(Arg497*) variant. At diagnosis, his bone marrow cytogenetics showed 46,XY,t(3;21)(q26;q22), del(7)(q11.2q32)[28]/46,XY[5].

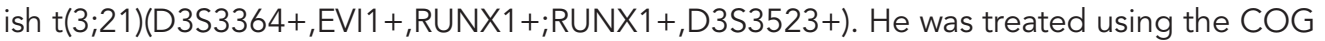
AAML1031 protocol. He had new onset grand mal seizures during chemotherapy and was treated with levetiracetam and has continued on this medication. 
COLD SPRING HARBOR Molecular Case Studies
Clinical features of patients with CHAMP1 variants
At the age of $8.5 \mathrm{yr}$ he had an allogeneic stem cell transplantation. He relapsed 27 mo after the first transplant with additional cytogenetic changes with a new clone, with no central nervous system (CNS) involvement. He was treated according to the acute myeloid leukemia (AML) relapse therapy protocol including FLAG (fludarabine, cytarabine, granulocyte colony-stimulating factor) therapy and a gemtuzumab/cytarabine combination. He had poor bone marrow recovery at the end of the gemtuzumab/cytarabine cycle, and his bone marrow showed $>20 \%$ leukemic blasts and hypocellularity consistent with refractory AML. The bone marrow cytogenetics at relapse demonstrated 46,XY,t(3;21)(q26;q22), del(7)(q11.2q32), $\operatorname{der}(20) t(1 ; 20)(q 25 ; p 11.2)[17] / / 46, X X[2]$.ish $\operatorname{der}(20) t(1 ; 20)(w c p 1+; w c p 20+) \times 2[6]$.

He received a haploidentical hematopoietic stem cell transplantation (HSCT) in aplasia induced by clofarabine. He received a bone marrow transplant from his father at $11 \mathrm{yr}$ old. At this time, his bone marrow aspiration was consistent with remission and full chimerism, but he had a de novo del(20)(q11.2q13.1) of unknown significance not present in his father. Soon after transplant he developed thrombocytopenia, and his bone marrow aspirate showed remission and full chimerisms from the donor with persistence of the del(20)q (46, $X Y$,del(20)(q11.2q13.1)[12]/46,XY[13].nuc ish(D7Z1,D7S486)x2[200])). No other abnormalities were observed. His complete blood count is normal with no evidence of leukemia or myelodysplastic syndromes (MDS). He developed graft versus host disease of the oral mucosa and skin and was treated with oral budesonide and sirolimus systemically. He is discontinued from immunosuppression and currently asymptomatic without any signs of graft versus host disease.

\section{DISCUSSION}

CHAMP1 is a zinc finger protein with five C2H2-type zinc finger motifs (Itoh et al. 2011). Twenty-four de novo pathogenic/likely pathogenic variants in CHAMP1 have been described: one missense, one microdeletion, eight frameshift, and 14 nonsense. The first reported missense variant (Ben-Haim et al. 2020) has multiple lines of computational evidence supporting a deleterious effect (PP3), is absent in controls (PM2), has confirmed de novo inheritance via parental DNA analysis (PS2), and is likely pathogenic by the American College of Medical Genetics and Genomics/American Molecular Pathology criteria (Richards et al. 2015). All other reported variants are null, pathogenic, or likely pathogenic variants and are predicted to cause loss of function leading to haploinsufficiency. To date there are no obvious genotype-phenotype correlations. Previous studies reported a recurrent CHAMP1 variant in two individuals c.1192C > T; p.(Arg398*) (Hempel et al. 2015). Two other previously reported individuals have different DNA variants, c.1044delG (Tanaka et al. 2016) and c.1043G > A (Isidor et al. 2016), leading to the same protein variant, p.(Trp348*). There are two individuals with a de novo c.542_543delCT, p.(Ser181Cysfs*5) variant: one in our cohort and one previously reported (Tanaka et al. 2016). We also reported two unrelated individuals who carry the same de novo variant: c.2127T> G; p.(Y709*). Additionally, there are five individuals with a de novo c.1489C > T; p.(Arg497*) variant: four in our cohort and one previously reported (Isidor et al. 2016). This is likely due to a C $>\mathrm{T}$ transition at a CpG dinucleotide that occurs in $25 \%$ of de novo germline mutations (Hodgkinson et al. 2009; Alexandrov et al. 2013; Acuna-Hidalgo et al. 2016). Our findings identify a few mutational hotspots in CHAMP1.

In this study, we report 14 individuals with de novo pathogenic CHAMP1 variants. Of these 14 individuals, 12 have not previously been described. The clinical manifestations of those in our cohort are similar to those previously described (Hempel et al. 2015; Isidor et al. 2016; Tanaka et al. 2016; Okamoto et al. 2017; Ben-Haim et al. 2020). All individuals have developmental delay or intellectual disability, hypotonia, and ophthalmologic issues 
(i.e., hyperopia, strabismus, and nystagmus). Most of the individuals have gastrointestinal problems, primarily GERD and constipation. Other notable features include congenital and acquired microcephaly, feeding difficulties, ASD, and high pain tolerance. The positive correlation between CHAMP1 and the development of a neurodevelopmental phenotype was also mentioned in a study that collected 60 patients who have 13q33-q34 microdeletions (Sagi-Dain et al. 2019).

Two individuals with a CHAMP1 variant were reported to have ASD (Hempel et al. 2015; Isidor et al. 2016) compared to the five in our cohort of 14 . Short stature and difficulty gaining weight have been more variable across the small clinical series and present in $20 \%-40 \%$ of individuals (Hempel et al. 2015; Isidor et al. 2016; Okamoto et al. 2017; Ben-Haim et al. 2020).

Seizures have recently been recognized to be associated with CHAMP1 variants (BenHaim et al. 2020) and are associated with a variety of seizure types including nocturnal frontotemporal epilepsy ( $n=1$; Hempel et al. 2015), febrile seizures ( $n=1$; Tanaka et al. 2016), generalized seizures ( $n=1$; Tanaka et al. 2016), complex partial seizures $(n=1$; Okamoto et al. 2017), and refractory myoclonic epilepsy ( $n=2$; Ben-Haim et al. 2020).

Problems with sleep may require further characterization. In addition to the five individuals (35.7\%) with sleeping difficulties on our cohort, Hempel et al. (2015) reported three cases with sleeping difficulties (60\%), one with sleep disturbance without successful treatment of melatonin, one with obstructive sleep apnea, and one with sleep apnea associated with nocturnal frontotemporal epilepsy. Four of the five individuals reported in Tanaka et al. (2016) had problems falling asleep and staying asleep. Based on the VABS behavior assessment, most individuals demonstrated challenges across communication, daily living, socialization, and motor skills. There was a significant negative correlation between the age of the individual at the time of the assessment and the VABS standardized adaptive behavior composite, communication, daily living skills, and socialization scores. We have not observed developmental regression over time. Rather, with age, individuals with the CHAMP1 pathogenic variants further diverged from their peers. Of the three subscales, the daily living skills score was the lowest and socialization was the highest. Many individuals had ASD and/or attention-deficit/hyperactivity.

CHAMP1 defects affect kinetochore-microtubule attachment, resulting in abnormal chromosome alignment along the metaphase plate, impairing chromosomal segregation and multipolar spindle formation leading to apoptosis or cytokinesis failure of neuronal progenitor cells (NPCs) during embryogenesis (Itoh et al. 2011; Okamoto et al. 2017). The disrupted protein interactions between CHAMP1 and other microtubule and/or kinetochore protein networks, specifically BUBR1 and MAD2L2, may also play a role in the pathogenesis of cancer (Fig. 3). BUB1B encodes BUBR1, a mitotic spindle checkpoint protein important for triggering apoptosis in polyploid cells and inhibiting tumor growth (Tang et al. 2001; Shin et al. 2003). Biallelic BUB1B variants are associated with the cancer susceptibility disorder called mosaic variegated aneuploidy (MVA). MVA manifests as childhood cancers (i.e., Wilms tumor, rhabdomyosarcoma, and leukemia) in $~ 40 \%$ of individuals (Ganmore et al. 2009; Suijkerbuijk et al. 2010).

Genes associated with microtubule networks have been reported to cause neurodevelopmental disorders including lissencephaly, polymicrogyria, autism spectrum disorders, and intellectual disabilities (Lasser et al. 2018). Additionally, kinetochore-associated gene variants that interact with CHAMP1 result in phenotypically similar neurodevelopmental conditions. These genes include CENP-E, CENP-F, BUBR1, CEP57, NDE1, and KNL1 (Fig. 3). Genetic variants in these corresponding genes result in genetic conditions with similar phenotypic manifestations such as microcephaly primary type 13 (OMIM \#616051), Strømme syndrome (OMIM \#243605), mosaic variegated aneuploidy syndrome 1 (OMIM \#602860), mosaic variegated aneuploidy syndrome 2 (OMIM \#614114), microhydranencephaly (OMIM \#605013), and microcephaly primary type 4 (OMIM \#604321). These conditions 
COLD SPRING HARBOR Molecular Case Studies
Clinical features of patients with CHAMP1 variants

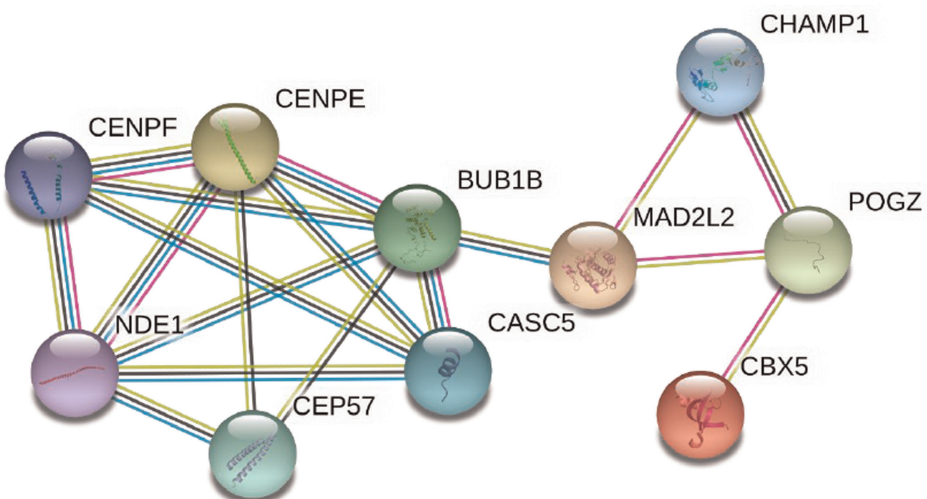

\begin{tabular}{|c|c|c|}
\hline Gene & Gene name & Disease name \\
\hline CHAMP1 & $\begin{array}{l}\text { Chromosome Alignment-maintaining } \\
\text { Phosphoprotein } 1\end{array}$ & Mental retardation, autosomal dominant 40 \\
\hline MAD2L2 & Mitotic Arrest-deficient 2 Like 2 & Fanconi anemia, complementation group $\mathrm{V}$ \\
\hline POGZ & $\begin{array}{l}\text { Pogo Transposable Element With Znf } \\
\text { Domain }\end{array}$ & White-Sutton syndrome \\
\hline KNL1(CASC5) & Kinetochore Scaffold 1 & Microcephaly 4, primary, AR \\
\hline CENPE & Centromeric Protein E & Microcephaly 13, primary, AR \\
\hline CENPF & Centromeric Protein F & Stromme syndrome \\
\hline BUBR1 & $\begin{array}{l}\text { Bub1 Mitotic Checkpoint } \\
\text { Serine/Threonine Kinase B }\end{array}$ & Mosaic variegated aneuploidy syndrome 1 \\
\hline CEP57 & Centrosomal Protein, 57-kd & Mosaic variegated aneuploidy syndrome 2 \\
\hline NDE1 & Nude Neurodevelopment Protein 1 & Microhydranencephaly \\
\hline HP1(CBX5) & Heterochromatin Protein 1 & Not identified \\
\hline
\end{tabular}

Figure 3. Protein interactors of CHAMP1 with associated conditions with the protein-protein interaction annotation produced by https://string-db.org/.

involve similar clinical features including microcephaly, intellectual disability, developmental delay, short stature, dysmorphic features, hypotonia, and ophthalmological issues (Kavaslar et al. 2000; Snape et al. 2011; Mirzaa et al. 2014; Filges et al. 2016; Saadi et al. 2016; Zaqout et al. 2017). Functional studies also demonstrate that CHAMP1 protein variants cannot bind to two of CHAMP1's partners: POGZ (pogo transposable element-derived protein with zinc finger domain) and HP1 (heterochromatin protein 1) (Isidor et al. 2016). De novo variants in POGZ are associated with developmental delay/intellectual disability, microcephaly, delayed onset of walking and talking, hypotonia, dysmorphic facial features, autism spectrum disorder, and failure to thrive (Ye et al. 2015), demonstrating similar clinical manifestations to those with CHAMP1 variants (Fig. 3).

We report one individual (I-7) with AML, the first report of cancer found in a patient who has a germline CHAMP1 variant. Our patient initially had a t(3;21)(q26.2;q22) translocation, which is associated with AML. Our patient relapsed after 27 mo following his second bone marrow transplant. At this time, the only cytogenetic difference was a novel interstitial deletion of Chromosome $20 \mathrm{q}$. This novel del(20q) may have been induced by his cancer treatment, resulting in a relapse of acute myeloid leukemia as seen in a similar report (Kanagal-Shamanna et al. 2013). However, previous studies also demonstrate late relapses are common in patients who receive transplantation for MDS (Yeung et al. 2015). New 
COLD SPRING HARBOR Molecular Case Studies
Clinical features of patients with CHAMP1 variants cytogenetic alterations that appear during a late relapse are usually due to the emergence of clones (Yeung et al. 2015) such as his del(20q). Typically, MDS with del(20q) has a good prognosis, but additional cytogenetic and molecular abnormalities may confer a worse prognosis (Bacher et al. 2014). In CHAMP1 haploinsufficiency, proper kinetochore-microtubule attachment and chromosome alignment are deranged, resulting in higher mitotic indices and chromosome instability (Itoh et al. 2011). This genetic instability may contribute to the manifestation of cancer. As we saw leukemia in only one patient, we need to consider that this may be a somatic change not associated with the germline CHAMP1 variant.

CHAMP1 also interacts with MAD2L2 (mitotic arrest deficient-like 2), a component of the mitotic spindle assembly checkpoint required for genomic integrity and associated with Fanconi anemia (Itoh et al. 2011; Gay 2018). Aberrant regulation of MAD2L2 has been demonstrated in many tumors including colon, breast, and ovarian (Niimi et al. 2014; Okina et al. 2015; Feng et al. 2016; Li et al. 2018). We believe that the dysfunctional connectivity between CHAMP1 and the complex microtubule/kinetochore protein networks contribute to the genomic instability required to predispose one to cancer.

In summary, pathogenic CHAMP1 variants cause a rare neurodevelopmental disorder associated with intellectual disability, speech and language impairment, microcephaly, seizures, hypotonia, ophthalmologic issues, constipation/gastroesophageal reflux, and behavioral problems including autism and sleep disturbances. We reported one case with childhood leukemia. We should continue to monitor for future reports of leukemia and other cancer phenotypes in individuals with CHAMP1 variants.

\section{METHODS}

This study was approved by the Columbia University Irving Medical Center Human Research Protection Institutional Review Board (Protocol Approved IRB\# AAAF3927). Written consent was obtained from all families. Twelve of the individuals joined the Simons VIP/Simons Searchlight study (https://www.simonssearchlight.org/). Participants underwent clinical whole-exome sequencing or gene panel sequencing for intellectual disability, developmental delay, autism spectrum disorder characteristics, and/or behavioral problems. Clinical exome sequencing coverage depth was $80 \times$ on average genome-wide. Genetic test reports were reviewed for eligibility based upon likely pathogenic/pathogenic variants in CHAMP1 using American College of Medical Genetics and Genomics/American Molecular Pathology criteria (Richards et al. 2015). Fourteen individuals were enrolled who have pathogenic or likely pathogenic variants in CHAMP1. Two individuals had been previously reported in the literature (individual 4 from Isidor et al. 2016; individual 12 from Tanaka et al. 2016) and 12 are new to the literature. Standardized medical histories were taken by genetic counselors by telephone interview. VABS was performed by telephone interview with a trained research assistant. The Rare Epilepsy Network seizure survey was performed online (https ://www.epilepsy.com/clinical_trials/rare-epilepsy-network).

\section{ADDITIONAL INFORMATION}

\section{Data Deposition and Access}

Whole-exome sequencing data are not publicly available because patient consents could not be obtained. The CHAMP1 variants found in this study have been deposited in ClinVar (http://www.ncbi.nlm.nih.gov/clinvar/) under accession numbers VCV000217909.3, VCV000827777.2, SCV001571201, VCV000210049.2, VCV000210050.4, VCV000217907.3, 
Competing Interest Statement

The authors have declared no competing interest.

Received March 2, 2021; accepted in revised form May 10, 2021.
VCV000984804.1, VCV000280855.3, VCV000217916.2, VCV000523879.4, and VCV00052 3879.4 .

\section{Ethics Statement}

This study was approved by the Institutional Review Board of Columbia University under the protocol number AAAF3927. Written consent was obtained from all families.

\section{Acknowledgments}

We thank the patients and their families for their generous contributions to share their medical information with our team. We also thank Simons Searchlight, an initiative of Simons Foundation Autism Research Initiative (SFARI), for their efforts to build strong partnerships between families and researchers and help increase our understanding of the CHAMP1 condition.

\section{Author Contributions}

M.L.G. and H.K. collected and analyzed the data and drafted and critically reviewed the manuscript. M.R-V., I.V., A.L., S.R., G.B., C.M., A.M., and B.I. provided clinical data and critically reviewed the manuscript. W.K.C. conceived of the study, provided clinical data, and drafted and critically reviewed the manuscript.

\section{Funding}

This work is supported by the Columbia University College of Dental Medicine Research Committee who awarded Madison Garrity Summer Fellowship Honors and grants from SFARI and the JPB Foundation.

\section{REFERENCES}

Acuna-Hidalgo R, Veltman JA, Hoischen A. 2016. New insights into the generation and role of de novo mutations in health and disease. Genome Biol 17: 241. doi:10.1186/s13059-016-1110-1

Alexandrov LB, Nik-Zainal S, Wedge DC, Aparicio SAJR, Behjati S, Biankin A V, Bignell GR, Bolli N, Borg A, Børresen-Dale A-L, et al. 2013. Signatures of mutational processes in human cancer. Nature 500: 415421. doi:10.1038/nature12477

Bacher U, Haferlach T, Schnittger S, Zenger M, Meggendorfer M, Jeromin S, Roller A, Grossmann V, Krauth MT, Alpermann T, et al. 2014. Investigation of 305 patients with myelodysplastic syndromes and $20 \mathrm{q}$ deletion for associated cytogenetic and molecular genetic lesions and their prognostic impact. Br J Haematol 164: 822-833. doi:10.1111/bjh.12710

Ben-Haim R, Heyman E, Benyamini L, Shapira D, Lev D, Tzadok M, Lerman-Sagie T, Saitsu H, Matsumoto N Iwama K, et al. 2020. CHAMP1 mutations cause refractory infantile myoclonic epilepsy. J Pediatr Neurol 18: 027-032. doi:10.1055/s-0039-1683449

Feng L, Wei W, Heng Z, Yantao H, Chunbo W. 2016. Knockdown of REV7 inhibits breast cancer cell migration and invasion. Oncol Res Featur Preclin Clin Cancer Ther 24: 315-325. doi:10.3727/ $096504016 \times 14666990347590$

Filges I, Bruder E, Brandal K, Meier S, Undlien DE, Waage TR, Hoesli I, Schubach M, de Beer T, Sheng Y, et al. 2016. Strømme syndrome is a ciliary disorder caused by mutations in CENPF. Hum Mutat 37: 359-363. doi:10.1002/humu.22960

Fitzgerald TW, Gerety SS, Jones WD, Van Kogelenberg M, King DA, McRae J, Morley KI, Parthiban V, Al-Turki S, Ambridge K, et al. 2015. Large-scale discovery of novel genetic causes of developmental disorders. Nature 519: 223-228. doi:10.1038/nature14135

Ganmore I, Smooha G, Izraeli S. 2009. Constitutional aneuploidy and cancer predisposition. Hum Mol Genet 18: R84-R93. doi:10.1093/hmg/ddp084

Gay S. 2018. A novel function for the mitotic checkpoint protein Mad2p in translation. Mol Cell Oncol 5: e1494949. doi:10.1080/23723556.2018.1494949 
Hempel M, Cremer K, Ockeloen CW, Lichtenbelt KD, Herkert JC, Denecke J, Haack TB, Zink AM, Becker J, Wohlleber $\mathrm{E}$, et al. 2015. De novo mutations in CHAMP1 cause intellectual disability with severe speech impairment. Am J Hum Genet 97: 493-500. doi:10.1016/j.ajhg.2015.08.003

Hodgkinson A, Ladoukakis E, Eyre-Walker A. 2009. Cryptic variation in the human mutation rate. PLoS Biol 7: e1000027. doi:10.1371/journal.pbio.1000027

Isidor B, Küry S, Rosenfeld JA, Besnard T, Schmitt S, Joss S, Davies SJ, Roger Lebel R, Henderson A, Schaaf CP, et al. 2016. De novo truncating mutations in the kinetochore-microtubules attachment gene CHAMP1 cause syndromic intellectual disability. Hum Mutat 37: 354-358. doi:10.1002/humu.22952

Itoh G, Kanno S, Uchida KSK, Chiba S, Sugino S, Watanabe K, Mizuno K, Yasui A, Hirota T, Tanaka K. 2011. CAMP (C13orf8, ZNF828) is a novel regulator of kinetochore-microtubule attachment. EMBO J 30: 130-144. doi:10.1038/emboj.2010.276

Kanagal-Shamanna R, Yin CC, Miranda RN, Bueso-Ramos CE, Wang XI, Muddasani R, Medeiros LJ, Lu G. 2013. Therapy-related myeloid neoplasms with isolated del(20q): comparison with cases of de novo myelodysplastic syndrome with del(20q). Cancer Genet 206: 42-46. doi:10.1016/j.cancergen.2012 .12 .005

Kavaslar GN, Önengüt S, Derman O, Kaya A, Tolun A. 2000. The novel genetic disorder microhydranencephaly maps to Chromosome 16p13.3-12.1. Am J Hum Genet 66: 1705-1709. doi:10.1086/302898

Lasser M, Tiber J, Lowery LA. 2018. The role of the microtubule cytoskeleton in neurodevelopmental disorders. Front Cell Neurosci 12: 165. doi:10.3389/fncel.2018.00165

Li Y, Li L, Chen M, Yu X, Gu Z, Qiu H, Qin G, Long Q, Fu X, Liu T, et al. 2018. MAD2L2 inhibits colorectal cancer growth by promoting NCOA3 ubiquitination and degradation. Mol Oncol 12: 391-405. doi:10.1002/18780261.12173

Mirzaa GM, Vitre B, Carpenter G, Abramowicz I, Gleeson JG, Paciorkowski AR, Cleveland DW, Dobyns WB, O'Driscoll M. 2014. Mutations in CENPE define a novel kinetochore-centromeric mechanism for microcephalic primordial dwarfism. Hum Genet 133: 1023-1039. doi:10.1007/s00439-014-1443-3

Niimi K, Murakumo Y, Watanabe N, Kato T, Mii S, Enomoto A, Asai M, Asai N, Yamamoto E, Kajiyama H, et al. 2014. Suppression of REV7 enhances cisplatin sensitivity in ovarian clear cell carcinoma cells. Cancer Sci 105: 545-552. doi:10.1111/cas.12390

Okamoto N, Tsuchiya Y, Kuki I, Yamamoto T, Saitsu H, Kitagawa D, Matsumoto N. 2017. Disturbed chromosome segregation and multipolar spindle formation in a patient with CHAMP1 mutation. Mol Genet Genomic Med 5: 585-591. doi:10.1002/mgg3.303

Okina S, Yanagisawa N, Yokoyama M, Sakurai Y, Numata Y, Umezawa A, Higashihara M, Murakumo Y. 2015. High expression of REV7 is an independent prognostic indicator in patients with diffuse large B-cell lymphoma treated with rituximab. Int J Hematol 102: 662-669. doi:10.1007/s12185-015-1880-3

Richards S, Aziz N, Bale S, Bick D, Das S, Gastier-Foster J, Grody WW, Hegde M, Lyon E, Spector E, et al. 2015. Standards and guidelines for the interpretation of sequence variants: a joint consensus recommendation of the American College of Medical Genetics and Genomics and the Association for Molecular Pathology. Genet Med 17: 405-423. doi:10.1038/gim.2015.30

Saadi A, Verny F, Siquier-Pernet K, Bole-Feysot C, Nitschke P, Munnich A, Abada-Dendib M, Chaouch M, Abramowicz M, Colleaux L. 2016. Refining the phenotype associated with CASC5 mutation. Neurogenetics 17: 71-78. doi:10.1007/s10048-015-0468-7

Sagi-Dain L, Goldberg Y, Peleg A, Sukenik-Halevy R, Sofrin-Drucker E, Appelman Z, Josefsberg BYS, BenShachar S, Vinkler C, Basel-Salmon L, et al. 2019. The rare 13q33-q34 microdeletions: eight new patients and review of the literature. Hum Genet 138: 1145-1153. doi:10.1007/s00439-019-02048-y

Shin H-J, Baek K-H, Jeon A-H, Park M-T, Lee S-J, Kang C-M, Lee H-S, Yoo S-H, Chung D-H, Sung Y-C, et al. 2003. Dual roles of human BubR1, a mitotic checkpoint kinase, in the monitoring of chromosomal instability. Cancer Cell 4: 483-497. doi:10.1016/S1535-6108(03)00302-7

Snape K, Hanks S, Ruark E, Barros-Núñez P, Elliott A, Murray A, Lane AH, Shannon N, Callier P, Chitayat D, et al. 2011. Mutations in CEP57 cause mosaic variegated aneuploidy syndrome. Nat Genet 43: 527-529. doi:10 $.1038 /$ ng. 822

Sparrow SS, Cicchetti DV, Balla DA. 2005. Vineland adaptive behavior scales, 2nd ed. In American Guidance Service, Circle Pines, MN.

Srivastava S, Love-Nichols JA, Dies KA, Ledbetter DH, Martin CL, Chung WK, Firth HV, Frazier T, Hansen RL, Prock L, et al. 2019. Meta-analysis and multidisciplinary consensus statement: exome sequencing is a firsttier clinical diagnostic test for individuals with neurodevelopmental disorders. Genet Med 21: 2413-2421. doi:10.1038/s41436-019-0554-6

Suijkerbuijk SJE, van Osch MHJ, Bos FL, Hanks S, Rahman N, Kops GJPL. 2010. Molecular causes for BUBR1 dysfunction in the human cancer predisposition syndrome mosaic variegated aneuploidy. Cancer Res 70: 4891-4900. doi:10.1158/0008-5472.CAN-09-4319

Tanaka AJ, Cho MT, Retterer K, Jones JR, Nowak C, Douglas J, Jiang Y-H, McConkie-Rosell A, Schaefer GB, Kaylor J, et al. 2016. De novo pathogenic variants in CHAMP1 are associated with global developmental 
COLD SPRING HARB OR

Molecular Case Studies
Clinical features of patients with CHAMP1 variants delay, intellectual disability, and dysmorphic facial features. Mol Case Stud 2: a000661. doi:10.1101/mcs .a000661

Tang Z, Bharadwaj R, Li B, Yu H. 2001. Mad2-independent inhibition of APC ${ }^{\text {Cdc20 }}$ by the mitotic checkpoint protein BubR1. Dev Cell 1: 227-237. doi:10.1016/S1534-5807(01)00019-3

Wang M-M, Zhu D-N, Li S-S, Zhang G-Y, Yang L, Zhao Y-X, Liu H-Y. 2020. [Autosomal dominant intellectual disability-40 caused by a de novo mutation of the CHAMP1 gene: a case report]. Zhongguo Dang Dai Er Ke Za Zhi 22: 1131-1134.

Ye Y, Cho MT, Retterer K, Alexander N, Ben-Omran T, Al-Mureikhi M, Cristian I, Wheeler PG, Crain C, Zand D, et al. 2015. De novo POGZ mutations are associated with neurodevelopmental disorders and microcephaly. Mol Case Stud 1: a000455. doi:10.1101/mcs.a000455

Yeung CCS, Gerds AT, Fang M, Scott BL, Flowers MED, Gooley T, Deeg HJ. 2015. Relapse after allogeneic hematopoietic cell transplantation for myelodysplastic syndromes: analysis of late relapse using comparative karyotype and chromosome genome array testing. Biol Blood Marrow Transplant 21: 1565-1575. doi:10.1016/j.bbmt.2015.04.024

Zaqout S, Morris-Rosendahl D, Kaindl A. 2017. Autosomal recessive primary microcephaly (MCPH): an update. Neuropediatrics 48: 135-142. doi:10.1055/s-0037-1601448 


\section{COLD SPRING HARBOR Molecular Case Studies}

\section{Neurodevelopmental phenotypes in individuals with pathogenic variants in CHAMP1}

Madison Garrity, Haluk Kavus, Marta Rojas-Vasquez, et al.

Cold Spring Harb Mol Case Stud 2021, 7: a006092 originally published online May 21, 2021

Access the most recent version at doi: $10.1101 / \mathrm{mcs} . a 006092$
Supplementary http://molecularcasestudies.cshlp.org/content/suppl/2021/06/01/mcs.a006092.D Material C1

References This article cites 34 articles, 3 of which can be accessed free at: http://molecularcasestudies.cshlp.org/content/7/4/a006092.full.html\#ref-list-1

License This article is distributed under the terms of the Creative Commons Attribution-NonCommercial License, which permits reuse and redistribution, except for commercial purposes, provided that the original author and source are credited.

Email Alerting Receive free email alerts when new articles cite this article - sign up in the box at the Service top right corner of the article or click here. 